\title{
Successful Outcome After Intravenous Gasoline Injection
}

\author{
Wolfgang Domej, $M D^{a}$, Heike Mitterhammer, $M D^{b}$, Rudolf Stauber, $M D^{b}$, \\ Peter Kaufmann, $M D^{b}$, Karl Heinz Smolle, $M D^{b}$
}

aPulmonary Division, Department of Internal Medicine, Medical University of Graz, Austria

bIntensive Care Unit, Department of Internal Medicine, Medical University of Graz, Austria

\begin{abstract}
Introduction: Gasoline, ingested intentionally or accidentally, is toxic. The majority of reported cases of gasoline intoxication involve oral ingestion or inhalation. Data are scarce on complications and outcomes following hydrocarbon poisoning by intravenous injection.

Case Report: Following a suicide attempt by intravenous self-injection of $10 \mathrm{ml}$ of gasoline, a 26-year-old medical student was admitted to the intensive care unit (ICU) with hemoptysis, symptoms of acute respiratory failure, chest pain, and severe abdominal cramps. Gas exchange was severely impaired and a chest x-ray indicated chemical pneumonitis. Initial treatment consisted of mechanical ventilation, supportive hyperventilation, administration of nitrogen oxide (NO), and prednisone. Unfortunately, the patient developed multi-organ dysfunction syndrome (MODS) complicated by life-threatening severe vasoplegia within 24 hours after gasoline injection. High doses of vasopressors along with massive amounts of parenteral fluids were necessary. Despite fluid replacement, renal function worsened and required hemofiltration on 5 sequential days. After 12 days of intensive care management, the patient recovered completely and was discharged to a psychiatric care facility.

Discussion: Intravenous gasoline injection causes major injury to the lungs, the organ bearing the first capillary bed encountered. Treatment of gasoline poisoning is symptomatic because no specific antidote is available. Early and aggressive supportive care may be conducive to a favorable outcome with minimal residual pulmonary sequelae.
\end{abstract}

\section{INTRODUCTION}

Many constituents of gasoline such as benzene, toluene, xylene, butadiene, and others are toxic to humans [1,2]. Hydrocarbon poisoning and gasoline intoxication usually occur by inhalation or occupational percutaneous absorption [3-5]. Because of its volatility, gasoline is not readily absorbed through the intact skin, but it can be absorbed more efficiently by the lungs and the gastrointestinal tract [6]. Adults usually ingest gasoline for the purpose of self-harm and children may ingest accidentally [7-10]. Exposure to gasoline vapors at filling stations is suggested to be carcinogenic $[11,12]$. Higher levels of gasoline components in the blood were demonstrated in people who were briefly exposed to low-level carcinogens and potentially toxic compounds while filling gas tanks [4]. The systemic toxic effect of gasoline vapor inhalation mainly damages the lung tissue, central nervous system, myocardium, kidney, liver and adipose tissue [13]. The most serious side effect is aspiration pneumonia. Secondary effects include hypoxemia, infection, pneumatocele formation and chronic lung dysfunction [14, 10,13]. Inhalation abuse of volatile solvents or gas sniffing is more common and typically pursued by adolescents. Maruff et al. reported neurological and cognitive abnormalities associated with chronic gas sniffing; abnormalities include psychomotor retardation, drowsiness, delirium or stupor

Keywords: intravenous gasoline injection, attempted suicide, hemorrhagic and chemical pneumonitis

Notes: There was no outside funding of any kind used for this study.

Acknowledgments: We are indebted to Eugenia Lamont (native speaker), BA, and former Senior Technical Editor, Library of Congress, Washington, DC, for language editing of the manuscript.

Corresponding Author: Wolfgang Domej, MD, Pulmonary Division, Department of Internal Medicine, Medical University of Graz, Auenbruggerplatz 20, A-8036 Graz, Austria. Email: wolfgang.domej@meduni-graz.at 
[15]. Inhalative hydrocarbon poisoning may also result in euphoria, cardiac dysrhythmias, and respiratory arrest [16]. Morley et al. reported three cases of severe xylene poisoning with acute pulmonary edema [17]. Renal tubular damage and central nervous system disorders have been attributed to toluene exposure [18].

\section{CASE REPORT}

A previously healthy male medical student (age 26 years, height $174 \mathrm{~cm}$, weight $74 \mathrm{~kg}$ ) had tried to commit suicide by injecting $10 \mathrm{ml}$ of commercial gasoline [research octane number (RON): 98, unleaded Shell Super] into his left cubital vein one hour before admission to the ICU. The patient was in considerable distress but sufficiently alert enough to provide information on what had happened. He suffered from worsening dyspnea, chills, hemoptysis, bilateral pleuritic chest pain, and abdominal cramps. Upon physical examination, coarse breathing sounds and crackles at both lung bases were heard. There was a strong smell of gasoline on his breath. The injection site was slightly reddened but painless without any signs of necrosis. Initial blood pressure was $170 / 114 \mathrm{mmHg}$, heart rate $146 / \mathrm{min}$, respiration rate $40 / \mathrm{min}$ and skin temperature $36.8^{\circ} \mathrm{C}$.

Upon admission, cardiac monitoring and electrocardiogram (ECG) showed rapid atrial fibrillation at 130 to 160 beats/min and the chest $\mathrm{x}$-ray revealed interstitial as well as alveolar opacities in both lungs (Figure 1). Laboratory findings were unremarkable except for lactate dehydrogenase (LDH) 369 U/L (120-240) and lactate $2.2 \mathrm{mmol} / \mathrm{L}(<2)$, moderate leukocytosis of $17.1 \mathrm{G} / \mathrm{L}$, neutrophilia and left shift with $85 \%$ neutrophils, relative lymphopenia, platelets $231,000 \mathrm{G} / \mathrm{L}$, hematocrit 50.6\% (40-50\%), and hemoglobin $18.0 \mathrm{~g} / \mathrm{dL}$ (13-17). After ventilation with an inspired oxygen fraction $\left(\mathrm{FiO}_{2}\right)$ of 0.36 , arterial blood gases indicated global respiratory failure [arterial oxygen tension $\left(\mathrm{paO}_{2}\right): 55 \mathrm{mmHg}$; arterial carbon dioxide tension $\left(\mathrm{paCO}_{2}\right): 57 \mathrm{mmHg}$; arterial oxygen saturation $\left(\mathrm{SaO}_{2}\right)$ : 84\%] and combined respiratory-metabolic acidosis (arterial pH: 7.19, BE: $-7.8 \mathrm{HCO}_{3}{ }^{-}: 17.0$ ) (Figure 3). On admission, serum electrolytes and renal function parameters were within normal limits. The patient was immediately intubated and hyperventilated to accelerate elimination of volatile hydrocarbons. Supportive treatment consisted of a protective ventilatory strategy with low tidal volume ventilation following the protocol developed by the National Institutes of Health Acute Respiratory Distress Syndrome Network [19]. Intermediate prone positioning and NO application were intended to improve oxygenation. Despite adequate ventilation, gas exchange deteriorated. Severe ARDS could not be delayed and extensive bilateral hemorrhagic pleural effusions developed concomitantly. An average of one liter of hemorrhagic pleural effusion was withdrawn by thoracentesis from the right pleural space on each of the first three days. CT images of the thorax showed severe, sometimes patchy consolidations, hypoventilated areas and reticulo-nodular opacities in both lungs consistent with ARDS, and distinct bilateral pleural effusions (Figure 2). Fiberoptic bronchoscopy confirmed hemorrhagic bronchopneumonia with signs of diffuse mucosal hemorrhage in both

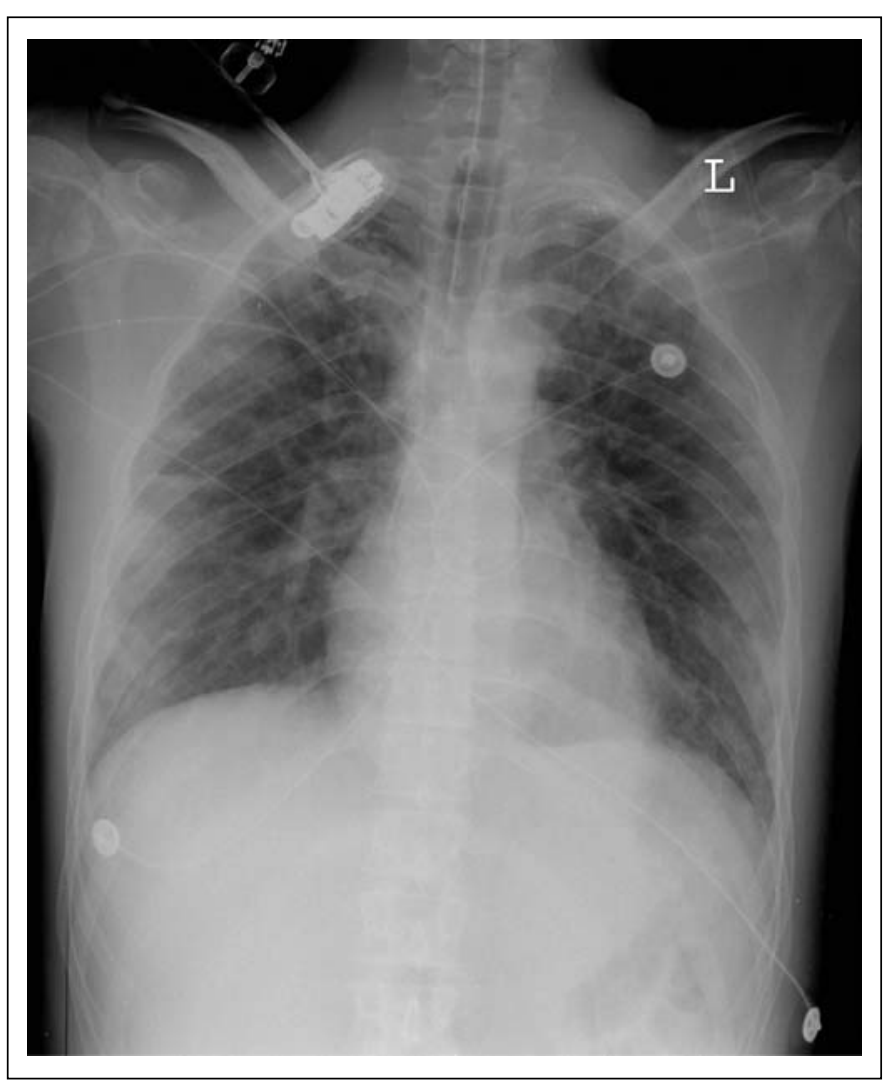

Figure 1: Chest x-ray: Small alveolar and interstitital opacities mainly in the periphery of both lungs.

lungs. Fungal and bacterial cultures from bronchoscopic brushings, lavage, and tracheal aspirations remained negative, and therapy with a broad spectrum antibiotic initiated empirically was discontinued. After six days in the ICU, pulmonary infiltrates decreased, $\mathrm{SaO}_{2}$ improved, and the inspiratory-ventilation pressures and the $\mathrm{FiO}_{2}$ could be gradually reduced (Figure 3 ). Mechanical ventilation was discontinued on the ninth day.

Besides respiratory failure, MODS developed within 24 hours of admission. Severe hypotension aggravated the course by causing toxic vasoparalysis lasting more than 72 hours. By substitution with crystalline and colloidal liquids $(12 \mathrm{~L} / 24 \mathrm{hr})$ as well as high doses of vasopressors (epinephrine: $0.98 \mu \mathrm{g} / \mathrm{kg} / \mathrm{min}$, dopamine: $4.3 \mu \mathrm{g} / \mathrm{kg} / \mathrm{min}$, dobutamine: $1.9 \mu \mathrm{g} / \mathrm{kg} / \mathrm{min}$ ), we maintained a mean arterial blood pressure of $60 \mathrm{mmHg}$. This severe arterial hypotension contributed to acute oligoanuric renal failure which was aggravated by rhabdomyolysis with a maximum creatinine kinase (CK) value of $3.290 \mathrm{U} / \mathrm{L}$ (10-80) and a myoglobin peak of $>3.017 \mathrm{ng} / \mathrm{ml}$ on the 4 th day in the ICU $(<90 \mathrm{ng} / \mathrm{ml})$. Acute renal failure went into a polyuric phase and continuous veno-venous hemofiltration was required for several days. By day 12, all renal parameters had normalized. On the third day after poisoning, a transient elevation of liver function parameters showed peak values for transaminases [alanin-aminotransferase (ALAT): 3.099, aspartate-amino-transferase (ASAT) 


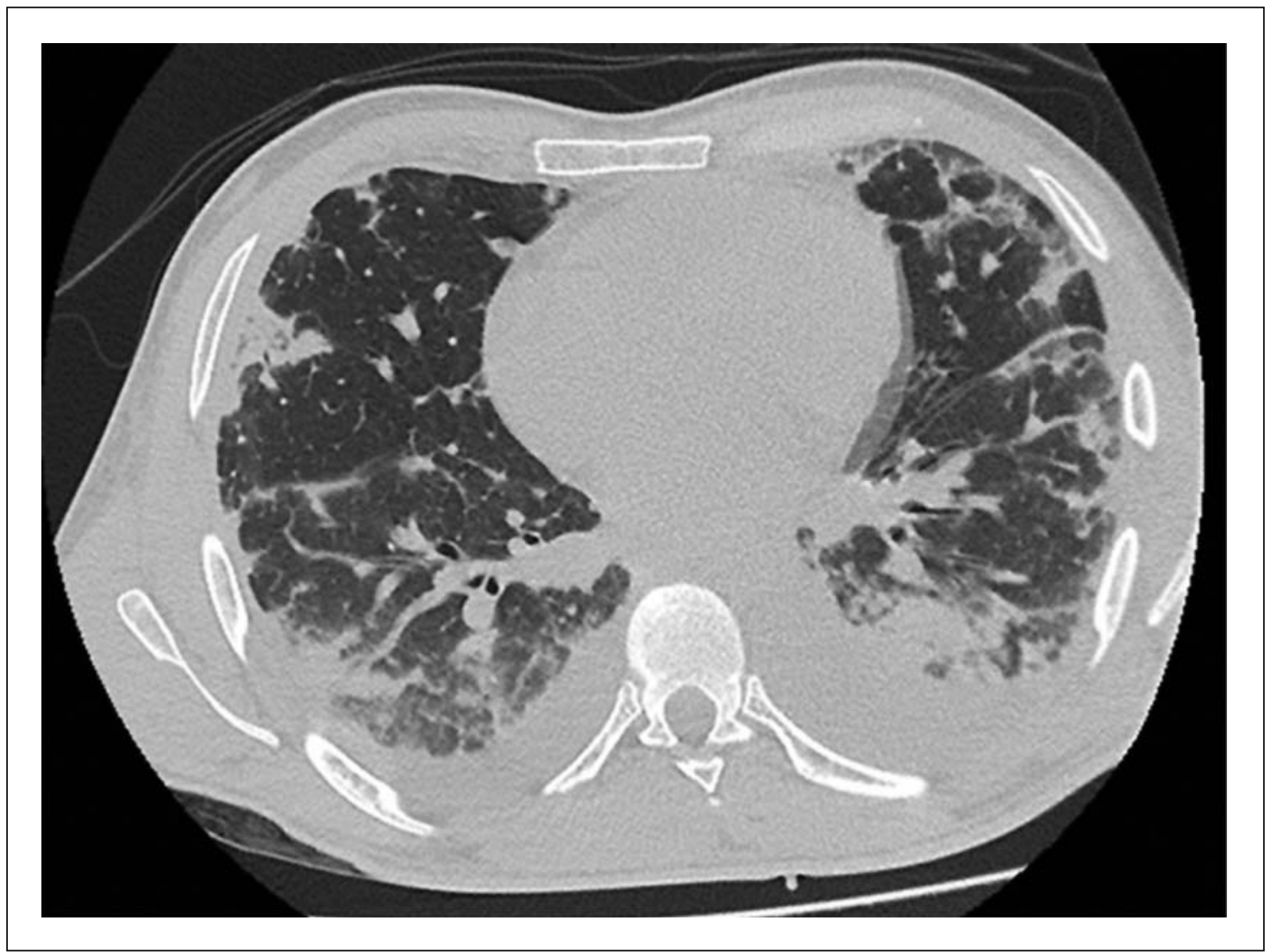

Figure 2: CT chest scan: Multiple patchy peripheral consolidations and some reticular-nodular densities, also in central areas of the lung, accompanying pronounced pulmonary involvement after intravenous gasoline injection. Distinct bilateral pleural effusions, cava catheter on right side.

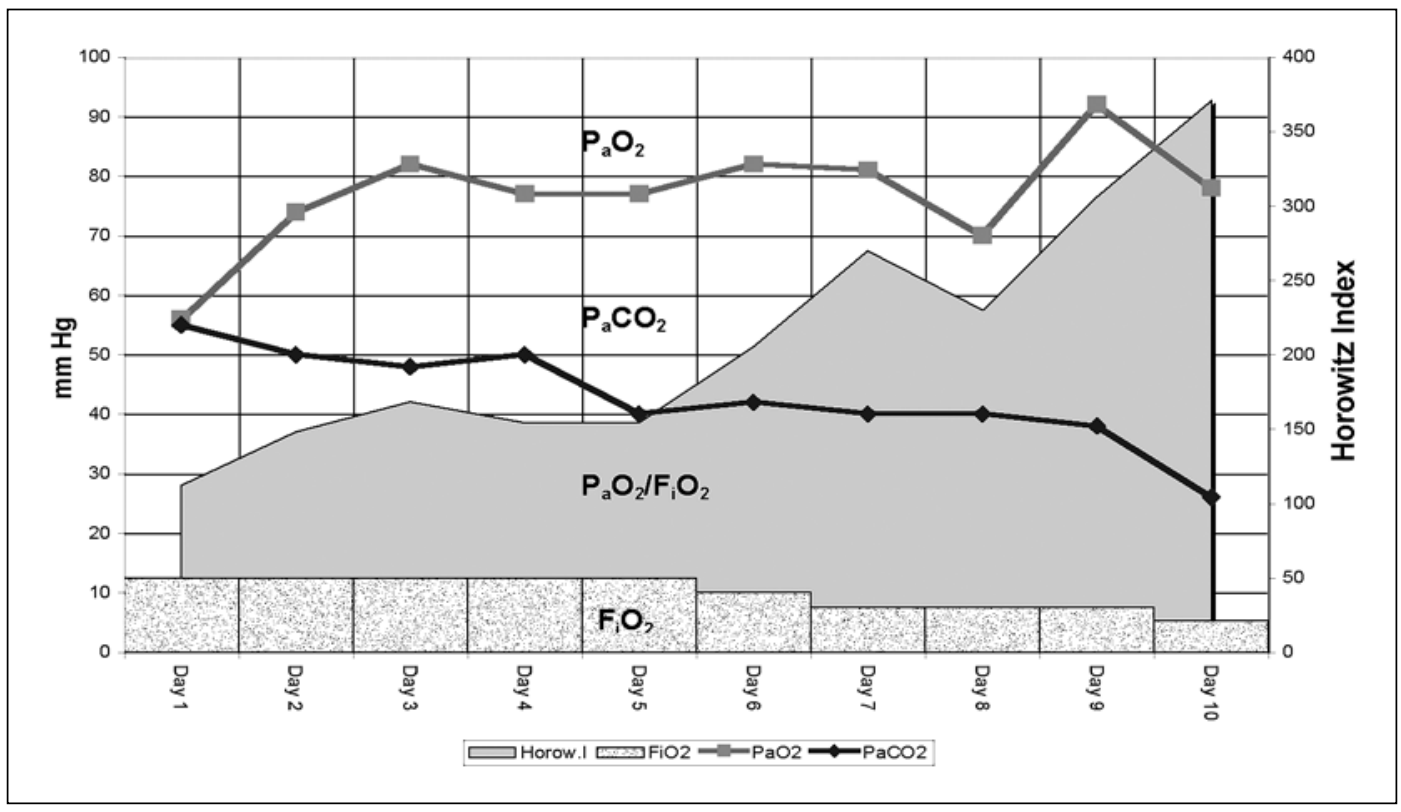

Figure 3: Course of Arterial Partial Pressures for paO2 and paCO2. Horowitz Index: paO2/FiO2. 
2.208 U/L]; gamma-glutamyl-transferase (GGT), alkaline phosphatase, and bilirubin remained within normal limits. Blood coagulation was also transiently impaired with an INR of 3.12 and 3.06 on the first two days, respectively. Transaminases gradually decreased and remained normal from day 12. Further recovery was unremarkable.

Upon follow-up 6 months later, MODS had completely resolved. A chest X-ray showed distinct diffuse nodular and reticular opacities and post-inflammatory residuals. Pulmonary function tests revealed moderate restriction with reduced CO-diffusing capacity, and reduction of forced vital capacity (FVC) and forced expiratory volume in one second $\left(\mathrm{FEV}_{1}\right)$. However, arterial blood gases at rest were normal $\left[\mathrm{paO}_{2}: 85 \mathrm{~mm} \mathrm{Hg}, \mathrm{paCO}_{2}: 37.6 \mathrm{~mm} \mathrm{Hg}\right.$, alveolar-arterial oxygen tension $\left(\mathrm{AaDO}_{2}\right): 19 \mathrm{~mm} \mathrm{Hg}, \mathrm{pH}$ 7.40].

\section{DISCUSSION}

Many constituents of gasoline such as benzene, toluene, xylene, butadiene, and others are toxic to humans [2]. Gasoline is a complex mixture of more than 500 hydrocarbons and additives with about $60-70 \%$ alkanes (paraffins), 25-30\% aromatics, and 6-9\% alkenes (olefins) [12]. Accidental hydrocarbon poisoning and gasoline intoxication usually occur by inhalation or by occupational percutaneous absorption [4,5]. Because of its volatility, gasoline is not readily absorbed through the intact skin, but it can be absorbed more efficiently by the lungs and the gastrointestinal tract [6]. Adults usually ingest gasoline for the purpose of self-harm, and children may ingest accidentally [7-10].

Reported cases of gasoline poisoning are scarce in the current medical literature. Intravenous or subcutaneous self-injections of commercial gasoline or kerosene with suicidal intent constitute extraordinary events in psychotic patients [3,20-26]. There are only four reports worldwide to date that discuss the toxic effects of intravenous gasoline injection. The first, in 1977 by Green, described a patient who survived a $3 \mathrm{~mL}$ intravenous injection of Energine, a kerosene derivate [27]. This patient developed lethargy, drowsiness, and a sterile abscess at the injection site without other systemic effects. Neeld and Vaziri each reported a case of intravenous injection of petroleum distillate that caused severe chemical pneumonitis. In both cases, pulmonary edema and hypoxemia developed, and in one, the patient suffered abrupt respiratory arrest immediately after injection $[27,28]$. Kosa reported an accidental intravenous injection of $10 \mathrm{ml}$ of gasoline that resulted in a fatal outcome [24]. His patient developed immediate tonic-clonic seizures, lost consciousness, and died within 40 minutes after the injection. The case strongly suggested that hydrocarbons, as low viscosity chemical compounds, have a direct toxic effect on lung tissue-interfering with gas exchange and leading to liquid interstitial pulmonary edema and severe hypoxemia caused by impaired diffusion. Larger intravenous doses of gasoline may cause sudden death from abrupt cardiac arrest, whereas smaller doses may induce chemical pneumonitis.

Previous reports of gasoline intoxication have not made clear which hydrocarbons are mainly responsible for the observed toxicity. Reese et al comprehensively reviewed the acute toxicity of gasoline and its components, benzene, toluene and xylene as well as the additives ethanol, methanol, and methyl-tertiarybutyl-ether [5].

In the present case, gasoline injected intravenously caused major injury to the lungs, the organ bearing the first capillary bed encountered. This is consistent with Bratton's experimental model [29]. Bratton demonstrated that injection of charcoal lighter fluid into a systemic vein caused severe pulmonary lesions, suggesting a confinement of the major pathology to the pulmonary system. The patient developed severe hypoxemia within one hour, followed by ARDS, and chemical hemorrhagic pneumonitis. Lung damage was associated with fever, leukocytosis, and hemorrhage, but there was no evidence of concomitant infection. The finding of numerous neutrophilic polymorphonuclear leukocytes in tracheal secretion in the absence of any bacterial pathogens indicated a noninfectious inflammatory process. Rao et al. also demonstrated an increase in the number of polymorphonuclear leukocytes and a reduction in the lymphocyte count following intraperitoneal injection of petroleum products in rats [16].

Leukocytosis is also commonly observed in severe pneumonitis associated with kerosene injection [30,31]. It seems likely that our patient's leukocytosis was primarily due to chemical lung injury. The associated temperatures may be observed in pneumonitis subsequent to intravenous gasoline application and do not necessarily indicate superimposed infection.

The toxicants were maximally absorbed and distributed in the pulmonary capillary bed, thereby causing severe damage to pulmonary epithelium and endothelium, lung inflammation, and dystelectasis due to lowered alveolar surfactant and elevated cytokine levels [32]. We assume that hypoxemia and endogenous oxidative stress caused enhanced release of inflammatory mediators, which could have augmented lung injury and the risk of non-pulmonary organ failure. Other effects of hydrocarbon intoxication include acute renal damage with oliguria, hepatocellular damage, intracellular hemolysis, gastric ulcers, and cardiac toxicity with negative inotropism.

In this case, the clinical course was further complicated by transient hepatic failure with marked elevation of transaminases and a moderate elevation of the international normalized ratio (INR). These alterations were self limited and resolved within 10 days. The hepatic damage may have been due to ischemic hepatitis in the context of vasoplegic shock and the direct toxic effect of gasoline components on hepatocytes. The cause of the patient's severe epigastric pain, which was a leading symptom in the early course of the illness, remains unclear. In view of the unremarkable abdominal examination, multiple negative stool tests for occult blood, and normal serum lipase and amylase levels, an intraabdominal etiology is unlikely. However, the pain could have originated in the thorax due to chemical pneumonitis and pleurisy and have been referred to the epigastric region.

This is the first report of successful therapeutic management of MODS following intravenous injection of gasoline. Treatment 
of gasoline poisoning is symptomatic because no specific antidote is available. Early and aggressive supportive care in the ICU may contribute to a favorable outcome with minimal residual pulmonary sequelae. Tissue injury mainly depends on the concentration of the toxic gasoline constituents and the duration of their presence in the circulation. Clinical management should include early intubation and controlled hyperventilation, consistent with the basic management of ARDS. Hyperventilation may help to accelerate elimination of volatile hydrocarbons, a measure that most likely mitigated the symptoms and improved the outcome of this unusual case.

The authors have no potential financial conflicts of interest to report.

\section{REFERENCES}

1. Geehr E. Management of hydrocarbon ingestions. Top Emerg Med. 1979;1:97-110.

2. Weaver NK. Gasoline toxicology: implications for human health. Ann NY Acad Sci. 1988;534:441-451.

3. Simay A, Szabo I, Deli L. Experimental contribution on acute changes in the airways during intravenous gasoline poisoning and their treatment. Arch Toxicol. 1968;23(3):250-252.

4. Backer LC, Egeland GM, Ashley DL, Lawryk NJ, Weisel CP, White MC, Bundy T, Shortt E, Middaugh JP. Exposure to regular gasoline and ethanol oxyfuel during refuelling in Alaska.

Environ Health Perspect. 1997;105(8):850-855.

5. Reese E, Kimbrough RD. Acute toxicity of gasoline and some additives. Environ Health Perspect. 1993;101 Suppl 6:115-131.

6. Wolfe BM, Brodeur AE, Shields JB. The role of gastrointestinal absorption of kerosene in producing pneumonitis in dogs. J Pediatr. 1979;76(6):867-873.

7. Truemper E, Reyes de la Rocha S, Atkinson SD. Clinical characteristics, pathophysiology, and management of hydrocarbon ingestion: case report and review of the literature. Pediatr Emerg Care. 1987;3(3):187-193.

8. Shotar AM. Kerosene poisoning in childhood: A 6-year prospective study at the Princes Rahmat Teaching Hospital. Neuro Endocrinol Lett. 2005;26(6):835-838.

9. Akamaguna AI, Odita JC. Radiology of kerosene poisoning in young children. Ann Trop Paediatr. 1983;3(2):85-88.

10. Arena JM. Hydrocarbon poisoning, current management. Pediatr Ann. 1987;16(11):879-883.

11. Mehlman MA. Dangerous and cancer-causing properties of products and chemicals in the oil refining and petrochenical industry: Part I. Carcinogenicity of motor fuels: gasoline. Toxicol Ind Health. 1991;7(6-5):143-152.

12. Page NP, Mehlman M. Health effects of gasoline refueling vapors and measurement exposures at service stations. Toxicol Ind Health. 1989;5(5):869-890.
13. Banner W Jr, Walson PD. Systemic toxicity following gasoline aspiration. Am J Emerg Med. 1983;1(3):292-294.

14. Campbell JB. Pneumatocele formation following hydrocarbon ingestion. Am Rev Respir Dis. 1970;101:414-418.

15. Maruff P, Burns CB, Tyler P, Currie BJ, Currie J.

Neurological and cognitive abnormalities associate with chronic petrol sniffing. Brain. 1998;121(Pt 10):1903-1917.

16. Rao GS, Dhasmana A, Kaw JL, Pandya KP, Zaidi SH. Toxicological studies on hydrocarbon-Iomex. Arc Environ Contam Toxicol. 1977;6(1):57-62.

17. Morley R, Eccleston DW, Douglas CP, Greville WE, Scott DJ, Anderson J. Xylene poisoning - a report on one fatal case and two cases of recovery after prolonged unconsciousness. Br Med J. 1970;3(720):442-443.

18. Cohr KH, Stokholm J.Toluene. A toxic review. Scand J Work Environ Health. 1979;5(2):71-71-90.

19. Acute Respiratory Distress Syndrome Network. Ventilation with lower tidal volumes for acute lung injury and the acute respiratory distress syndrome. The Acute Respiratory Distress Syndrome Network. N Engl J Med. 2000;342(18): 1301-1308.

20. Layton TR, Grant KJ, Villella ER. Gasoline injection. Clin Toxicol. 1983-1984;21(3):409-412.

21. Bucic M, Prohic H. A case of acute poisoning following intravenous injection of gasoline. Med Arh. 1960;14:11-17.

22. Bindlish V. Subcutaneous gasoline injection. Am J Emerg Med. 1993;11(6):676-677.

23. Beck DE, Freeman B, Moore CR. Toxicities with intravenous and subcutaneous administration of a petroleum distillate. Drug Intell Clin Pharm. 1981;15(9):693-694.

24. Kosa F. Indictment in a case of fatal intravenous petrol injection. Morphol Igazsagugyi Orv Sz. 1981;21(1):69-72.

25. Vaziri ND, Jeminson-Smith P, Wilson AF. Hemorrhagic pneumonitis after the intravenous injection of charcoal lighter fluid. Ann Intern Med. 1979;90(5):794-795.

26. Wason S, Greiner PT. Intravenous hydrocarbon abuse. Am J Emerg Med. 1986;4(6):543-544.

27. Green DO. Intravenous Energine-a case report. Clin Toxicol. 1977;10(3):283-286.

28. Neeld EM, Limacher MC. Chemical pneumonitis after the intravenous injection of hydrocarbon. Radiology.

1978; $129(1): 36$.

29. Bratton L, Haddow JE. Ingestion of Charcoal lighter fluid. J Pediatr. 1975;87(4):633-636.

30. Zucker AR, Berger S, Wood LD. Management of keroseneinduced pulmonary injury. Crit Care Med. 1986;14(4):303-304.

31. Busetti A, Ianeselli F..Respiratory insufficiency in a patient with exogenous poisoning caused by self-administration of intravenous kerosene. Minerva Anestesiol. 1984;50(3):73-76.

32. Roberts DJ, Davies JM, Evans CC, Bell M, Mostafa LM. Tumor necrosis factor and adult respiratory syndrome. Lancet. 1989;2:1043-1044. 